\title{
PREVALENCE OF DOG BITES IN A RURAL COMMUNITY: A 15 YEAR REVIEW OF CASES IN OKOYONG, CROSS RIVER STATE, NIGERIA.
}

\author{
M. ASUQUO, W. NDIFON, G. UGARE AND J. MWANKON
}

(Received 7 July, 2008; Revision Accepted 13 January, 2009)

\begin{abstract}
This retrospective study was undertaken to assess the prevalence of dog bites in Comprehensive Health Centre, Okoyong south-south Nigeria. Eleven cases of dog bite were recorded out of a total of 25,000 patients seen during a fifteen- year period (1990-2004). This gives a prevalence

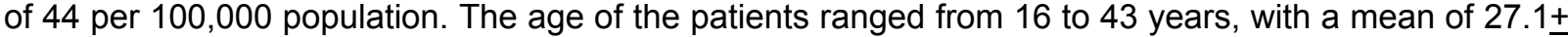
8.3. Male to female ratio was 1:0.8. The treatment of patients consisted of analgesics, antibiotics, tetanus toxoid and antitetanus serum. We did not have any recorded case of rabies, in spite of the fact that none of the patients had rabies vaccination nor antirabies immunoglobulin. All the patients reported late to hospital, the mean duration before presentation being 10.23 days. The follow up was extremely poor as most patients never reported for follow up after the initial treatment as outpatient or discharge following admission. We conclude that the prevalence of dog bites in this health centre is low $(0.04 \%)$.We recommend more comprehensive community-based studies to adequately assess the burden of this problem. Current regulations on the management of dog bites should be strictly followed by the attending medical personnel.
\end{abstract}

KEY WORDS: Okoyong, Dog bites, Prevalence.

\section{INTRODUCTION}

Man and dog have co-existed for thousands of years in a mutually beneficial manner, but occasionally problems arise. The commonest problem is that of a dog biting an individual and this phenomenon is worldwide (Ogun, 2008; Zanini, et al., 2008; Wright, 1985; Dwyer, et al, 2007). In our environment neither the prevalence, the characteristics of the dogs, the victims nor the lesions have been adequately documented.

In spite of the fact that dog bites are common in Nigeria (Ogun, 2001), most dogs are unvaccinated against rabies, and the supply of rabies vaccine per 1000 population is put at $10 \%$ or less (Fagbumi, et al, 1981).

Dog bites remain a common source of rabies both in the developed and developing countries of the world (Ogun, 2001; Georges and Adesiyun, 2008; Ghandi, et al., 1999) This is expected to be more common in a rural community because of the likelihood of a large proportion of unvaccinated dogs, ignorance of dangers of dog bites and inadequate health infrastructure to manage cases of dog bites.

This retrospective study was conducted in our centre to assess the prevalence of dog bites as well as to characterize the common sites, types of injuries and the socio-demographic characteristics of the affected individuals.

\section{SUBJECTS AND METHODS}

This study was carried out at the Okoyong Comprehensive Health Centre, located in Odukpani Local Government Area. of Cross River State, south-south Nigeria, and serves a

M. Asuquo, Department of Surgery, University of Calabar Teaching Hospital, Calabar, Nigeria

W. Ndifon, Department of Community Medicine, University of Calabar Teaching Hospital, Calabar, Nigeria

${ }^{*}$ G. Ugare, Department of Surgery, University of Calabar Teaching Hospital, Calabar, Nigeria

J. Mwankon, Department of Family Medicine, University of Calabar Teaching Hospital, Calabar, Nigeria. 
population of approximately 150,000 people mainly farmers. A consultant family physician heads the centre; assisted by a senior registrar, and a registrar. There are also various cadres of nursing and paramedical personnel.

Case records of patients who presented with a proven history of dog bite between January, 1990 and December, 2004 were used. Information extracted from them included the age and sex of the victims; history of the bite with regards to the site, type of injury, duration before presentation and any preliminary treatment. The type of treatment, outcome and follow-up at the centre were also noted. Statistical analysis was done using frequencies and percentages.

\section{RESULTS}

Out of a total 25,0000 patients seen during the fifteen-year period, $11(0.04 \%)$ of them had dog bites. Ten were farmers, the remaining a trader. The age and sex distribution of the victims is shown in Table1.The ages ranged from 16-43 years with a mean of $27.1+8.3$ and a male: female ratio of $1: 0.8$. Most of the bites, 4 (36.4\%), occurred in patients aged 21-30 years, followed by those in the $41-50$ year group with $3(27.3 \%)$. Those in the 11-20 and 31-40 years age brackets had equal number of bites, 2( $18.2 \%)$. No bite was recorded among patients aged 10 or less years. None of the dogs had a history of rabies vaccination.

\section{SITE OF BITE AND TYPE OF INJURIES}

Table 2 shows the site of bite, type of injury and number of patients involved. Two $(18.2 \%)$ of the patients were bitten on the upper limbs, both being right hands. Nine (81.8\%) were bitten on the lower limbs: one on both thighs, one on the left thigh; one on the left foot, two on the left legs and four on the right legs.

Seven were puncture wounds; four minor lacerations and, on one patient, a combination of two puncture wounds and a laceration.

\section{PREDISPOSING FACTORS TO BITE}

Seven $(63.6 \%)$ were due to provocation either by stepping on the dog, trying to catch its puppies, or attacking it directly for one reason or the other; while four bites were completely unprovoked. In one instance, the individual was bitten by a strange dog.

\section{TREATMENT OF INJURIES}

Most patients presented late; the mean duration before presentation at the clinic was 10.23 days, the median being 2 days.

All the patients gave a history of having received first aid from patent medicine vendors, consisting of washing the site with soap and administering analgesics and antibiotics often in wrong dosages and frequencies. Those who presented very late often had received additional treatment from traditional healers.

Only two were admitted for up to 48 hours for observation; the rest were managed as out patients. The treatment consisted of washing the site with an antiseptic solution, tetanus toxoid $0.5 \mathrm{ml}$ intramuscularly, antitetanus serum, antibiotic (often Ampiclox) an haematinics. Rabies vaccine and anti rabies immunoglobulin were not given. The patients were however asked to report back to clinic for check up within 3-4 days if they developed fever, headache and irritability; if the dog died or began to behave abnormally within 10-14 days. However, only two patients came back for checkup.

\section{DISCUSSION}

In the western industrialized countries, people keep dogs mainly as pets and for security reasons(Dwyer, et al, 2007;Ghanndi, et al,1999).In Nigeria and other African countries, most people keep dogs as pets, some for the purpose of hunting (Ogun, 2001; Fagbemi et al, 1981). A dog may bite an individual following provocation or a bite may be unprovoked.

Our investigation has revealed certain features that are both concordant and discordant with those of other authors. Majority of the bites in our study were in the lower $\operatorname{limbs}(81.8 \%)$, which agrees with the report of work done in Argentina(Zanini et al, 2008), but differs from it in another aspect: Zanini and colleagues reported that $49.5 \%$ of the cases were in children aged 59 years; we recorded no incident of dog bite in that age group. Although this difference can not be confidently explained by this investigation, it may be due to the fact that young children rarely play with dogs in our locality.. Zanini and coworkers also reported head and neck bites, which we did not. Since some people in our environment keep dogs for security purposes, bites will be more common in the lower than upper limbs. Head, neck and upper limb bites will, expectedly, be more common from playing with pet dogs than stepping or running from 
strange ones. More males than females were victims of dog bite in our study; a finding consistent with most reports (Dwyer, et al, 2008; Bernardo, et al, 2002; Mendez, et, al, 2002). Most of the victims were not owners of the dogs, but however knew their owners, and had previously seen the dog in that environment. This is also similar to the findings of other authors( Wright, 1985; Georges and Adesiyun, 2008). Georges and Adesiyun reported that a third $(33 \%)$ of the victims were bitten without having any interaction ( through provocation) with the dog; on the contrary, almost two thirds (63.6\%) of the victims in our study had an interaction with the dog. Thus we can say that most of the attacks in our study were due to provocation, contrary to what Ghandi and colleagues reported in Philadelphia, U.S.A, where $55 \%$ of the attacks were unprovoked.(Gandhi, et al, 1999).

Previous studies (Gandhi, et al, 1999; Bernardo, et al, 2002; Mendez, et al, 2002) reported a majority of laceration injuries, while we recorded mainly puncture wounds. Previous authors ( Bernardo et al, 2002; Mendez, et al, 2002; Dwyer, et al, 2007) were able to categorize the type of dog involved in the attack such as the German shepherds and the cross breeds; our patients were not able to such a detailed history, probably due to lack of awareness or knowledge.

The management of patients, from our investigation, consisted of wound lavage ( in fresh cases), analgesics, antibiotics, tetanus toxoid and antitetanus serum (ATS); which fell short of the current regulation of the management of dog and venomous bites (Ogun, 2001; Fagbumi, et al, 1981; Nawathe, 1980). The regulation stipulates that bites by such animals should, in addition, be treated with rabies vaccine in full dose (if the animal was not previously vaccinated) and rabies immunoglobulin in all victims. No patient in our study had rabies vaccination or immunoglobulin, and none of the dogs had a history of previous rabies vaccination. Our centre did not have any of these preparations in the pharmacy store at the time of the study.

Although we recorded a low prevalence rate of dog bites in this study, had these resulted in cases of rabies from unvaccinated dogs in such a small rural community, the mortality would have been unacceptably high. We therefore call on the state and local departments of health to educate the public on the dangers of dog bites. These departments should make rabies vaccine available at least in designated health facilities in both urban and rural areas. Dog bite victims can quickly be vaccinated and given rabies immunoglobulin. This is important in cases where the dog is unvaccinated or its vaccination status can not be proven; a situation that is very common in our environment. We also suggest that the veterinary section of the Ministry of Agriculture should make it mandatory that people keeping pets like dogs and cats should have them adequately vaccinated against rabies, with regulated periodic checkups to ensure compliance. We must remember that rabies has $100 \%$ mortality. (Nawathe, 1980; Fagbumi, et al, 1981).We also call for a Dog bite Act, which will make it mandatory for owners of dogs to treat victims of bites.

Udosen and colleagues (Udosen, et al, 2005) had earlier pointed out the limitations of traditional healers in the context of prevention of life- threatening conditions like tetanus and rabies We advocate that, since the primary concern in dog bites is not wound infection or pain management but the prevention rabies and/or tetanus, traditional healers and patent medicine vendors should be educated by the appropriate authorities at all levels that dog bite management is beyond their competence; victims should be promptly referred to the nearest health facility.

In spite of the low prevalence of dog bites in this health centre, the community prevalence may be higher, especially with the poor management and follow up from our review. Rabies can develop in an individual even after years following a bite by a rabid animal. We recommend that current regulations on the management of dog and venomous bites should be strictly followed, especially in the aspects of rabies vaccination and administration of rabies immunoglobulin. Being a facility-based study, the prevalence of dog bites could have been misleadingly low. Community-based studies on the prevalence of dog bites are therefore recommended as these will give a more correct situation of dog bites in this community.

\section{REFERENCES}

Bernardo, L. M., Gardner, M. J., Rosefield, R. L., Cohen, B. and Pitetti, R., 2002. A comparison of dog bite injuries in younger and older children treated in a paediatric emergency department. Paediatric Emergency Care.18(3):247-249 
Dwyer, J. P., Douglas, T. S. and van As, A.B., 2007. Dogbite injuries in children - a review from South African Paediatric trauma unit. S. Afr Med. J. 97(8);597-600

Fagbumi, A. H., Anosa, V. O. and Ezebuino E.O., 1981. Hospital Records of human rabies and antirabies prophylaxis in Nigeria: 19761978. Transaction of the Royal Society of Trop. Med. And Hyg. 75(6):25-30

Gandhi, R. R., Liebman, M. A., Stafford, B. C. and Stafford, P. W., 1999. Dog bite injuries in children: A preliminary Survey. Am. Surg. 65(9):863-864

Georges, K. and Adesiyun, A., 2008. An investigation into the Prevalence of dog bites to Primary School Children in Trinidad. BMC Public Health. 5(8):85

Mendez, G. R., Gomez, T. M., Somoza, A. I., Liras, M. J., Pais, P. E. and Vela, N. D., 2002. Dogbite related injuries treated in a Paediatric Surgery department: Analysis of 654 cases in 10 years. An. Esp. 56(5):425429

Nawathe, D. R., 1980. Rabies Control in Nigeria Bull. of Int. Epiz. 92:139

Ogun, S. A., 2001. Human Rabies- A review of current literature. Nigerian Medical Practitioner 40(1,2):3-5

Udosen, A. M., Ugare, U. G. and Ekpo, R., 2005. Tetanus complicating lower limb fractures managed traditional bone healers. Tropical doctor. 35:237-239.

Wright, J. C., 1985. Severe attack by dogs: characteristics of the dogs, the victims, and the settings. Public Health Rep. 100(1):55-61

Zanini, F., Padinger, P., Ellissondo, M. C. and Perez, H., 2008. Epidemiology of dog bite lesions in Tierra del Fuego, Argentina. Medicina (B. Aires) 68(1):1-5 
APPENDIX

TABLE 1: AGE AND SEX DISTRIBUTION OF PATIENTS WITH DOG BITES SEEN IN COMPREHENSIVE HEALTH CENTRE, OKOYONG, NIGERIA: 1990-2004.

\begin{tabular}{|l|l|l|l|}
\hline AGE(YRS) & \multicolumn{2}{l|}{ SEX } & TOTAL(\%) \\
& M & F & \\
\hline $0-10$ & 0 & 0 & $0(0.0)$ \\
\hline $11-20$ & 1 & 1 & $2(18.2)$ \\
\hline $21-30$ & 3 & 1 & $4(36.4)$ \\
\hline $31-40$ & 1 & 1 & $2(18.2)$ \\
\hline $41-50$ & 1 & 2 & $327.3)$ \\
\hline TOTAL & 6 & 5 & $11(100)$ \\
& & & \\
\hline
\end{tabular}

TABLE 2: SITE OF BITE, TYPE OF INJURY AND NUMBER OF PATIENTS INVOLVED.

\begin{tabular}{|l|l|l|}
\hline SITE OF BITE & TYPE OF INJURY & $\begin{array}{l}\text { NUMBER OF } \\
\text { PATIENTS (\%) }\end{array}$ \\
\hline Both upper limbs & $\begin{array}{l}\text { Puncture wounds and a } \\
\text { laceration on the right forearm }\end{array}$ & $2(18.2)$ \\
\hline Both thighs & Puncture wounds and lacerations & $1(9.1)$ \\
\hline Left thigh & Puncture wounds & $1(9.1)$ \\
\hline Left leg (calf) & Puncture wounds And lacerations & $2(18.2)$ \\
\hline Right leg (calf) & Puncture wounds and lacerations & $4(36.3)$ \\
\hline Left foot & Puncture wounds & $1(9.1)$ \\
\hline TOTAL & \multicolumn{1}{|}{$11(100)$} \\
\hline
\end{tabular}

